SUPPORTING INFORMATION

\title{
Fizzy Extraction of Volatile and Semivolatile Compounds into the Gas Phase
}

\author{
Cheng-Hao Chang, Pawel L. Urban*
}

Department of Applied Chemistry, National Chiao Tung University

1001 University Rd., Hsinchu, 300, Taiwan

* Corresponding author:

Dr P.L. Urban (plurban@nctu.edu.tw)

Contents:

- video file (S1)

- additional tables (S1, S2)

- additional figures (S1-S8) 
Movie S1 (separate file). Fizzy extraction of a blank sample (water:ethanol 95:5, v/v). The glass vial (extraction chamber) is placed inside an aluminum holder. Two transparent acrylic shields are installed in front of the viewing window to ensure safety. Stirring was switched off during this extraction to reveal bubble formation. 


\section{ADDITIONAL TABLES}

Table S1. Extraction/detection repeatability. Sample: $0.6 \mathrm{mM}$ limonene (dissolved in water:ethanol 95:5, v/v). MS signal: $\mathrm{m} / z 137\left(\left[\mathrm{C}_{10} \mathrm{H}_{16}+\mathrm{H}\right]^{+}\right)$. The RSD of average peak areas obtained on five days (reproducibility) is $7 \%$.

\begin{tabular}{cccc}
\hline Day & $\boldsymbol{n}$ & $\begin{array}{c}\text { Average peak } \\
\text { area / a.u. }\end{array}$ & RSD / \% \\
\hline 1 & 10 & 28995 & 6 \\
\hline 2 & 3 & 28200 & 13 \\
\hline 3 & 3 & 25887 & 6 \\
\hline 4 & 3 & 30520 & 19 \\
\hline 5 & 3 & 26077 & 10 \\
\hline
\end{tabular}


Table S2. Signal enhancement calculated for several model analytes, and their physical properties (approximate values based on various online sources and data sheets provided by the chemical supplier; temperature: $\sim 293 \mathrm{~K})$.

\begin{tabular}{|c|c|c|c|c|c|c|c|c|}
\hline Compound & Formula & $\begin{array}{c}\text { Molecular } \\
\text { weight } \\
\text { / u }\end{array}$ & $\begin{array}{l}\text { Boiling } \\
\text { point } \\
\text { / K }\end{array}$ & $\begin{array}{l}\text { Vapor pressure } \\
\qquad / \mathbf{k P a}\end{array}$ & $\begin{array}{c}\text { Surface } \\
\text { tension } \\
/ \mathrm{N} \mathrm{m}^{-1}\end{array}$ & $\begin{array}{l}\text { Solubility } \\
\text { in water } \\
/ \mathrm{g} \mathrm{kg}^{-1}\end{array}$ & $\begin{array}{c}\text { Concentration } \\
\text { in test sample } \\
/ \mathrm{mM}\end{array}$ & $\begin{array}{c}\text { Signal } \\
\text { enhancement }^{\star}\end{array}$ \\
\hline ethyl acetate & $\mathrm{C}_{4} \mathrm{H}_{8} \mathrm{O}_{2}$ & 88.11 & 351 & 9.7 & 0.024 & 83 & 1.00 & 1.1 \\
\hline hexyl acetate & $\mathrm{C}_{8} \mathrm{H}_{16} \mathrm{O}_{2}$ & 144.21 & 443 & 0.17 & 0.027 & 0.4 & 12.0 & 8.0 \\
\hline octyl acetate & $\mathrm{C}_{10} \mathrm{H}_{20} \mathrm{O}_{2}$ & 172.26 & 484 & 0.01 & 0.028 & 0.18 & 10.0 & 2.6 \\
\hline $\begin{array}{l}\text { ethyl } \\
\text { octanoate }\end{array}$ & $\mathrm{C}_{10} \mathrm{H}_{20} \mathrm{O}_{2}$ & 172.26 & 481 & 0.0027 & 0.028 & 83 & 4.98 & 8.5 \\
\hline limonene & $\mathrm{C}_{10} \mathrm{H}_{16}$ & 136.23 & 450 & 0.13 & 0.026 & 14 & 12.0 & 19.5 \\
\hline caffeine & $\mathrm{C}_{8} \mathrm{H}_{10} \mathrm{~N}_{4} \mathrm{O}_{2}$ & 194.19 & n.d. & $6.3 \times 10^{-7}$ & n.d. & 16 & 100 & 1.0 \\
\hline
\end{tabular}

* Extraction peak amplitude divided by headspace flushing peak amplitude. Solvent: water:ethanol 95:5 (v/v). n.d. - no data. 


\section{ADDITIONAL FIGURES}

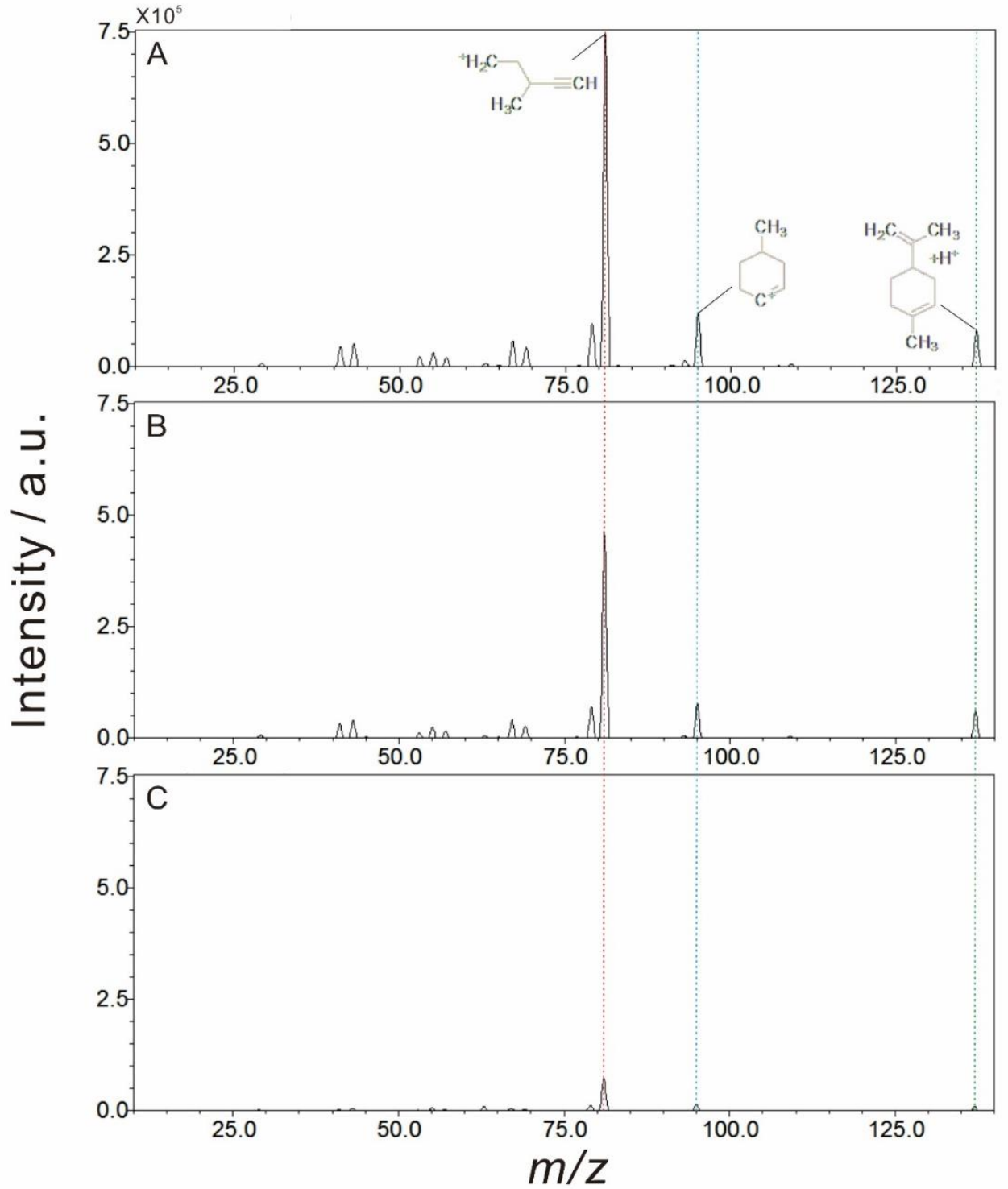

Figure S1. Tandem mass spectra obtained to confirm the identity of the limonene signal $(\mathrm{m} / \mathrm{z} 137)$ in the analyzed real samples: (A) $3 \mathrm{mM}$ limonene standard dissolved in water:ethanol 95:5, v/v; (B) lime juice ( $c f$. Figure 3E); (C) lime peel extract ( $c f$. Figure 3F). CID gas: argon. Collision voltage: $-20 \mathrm{~V}$. 


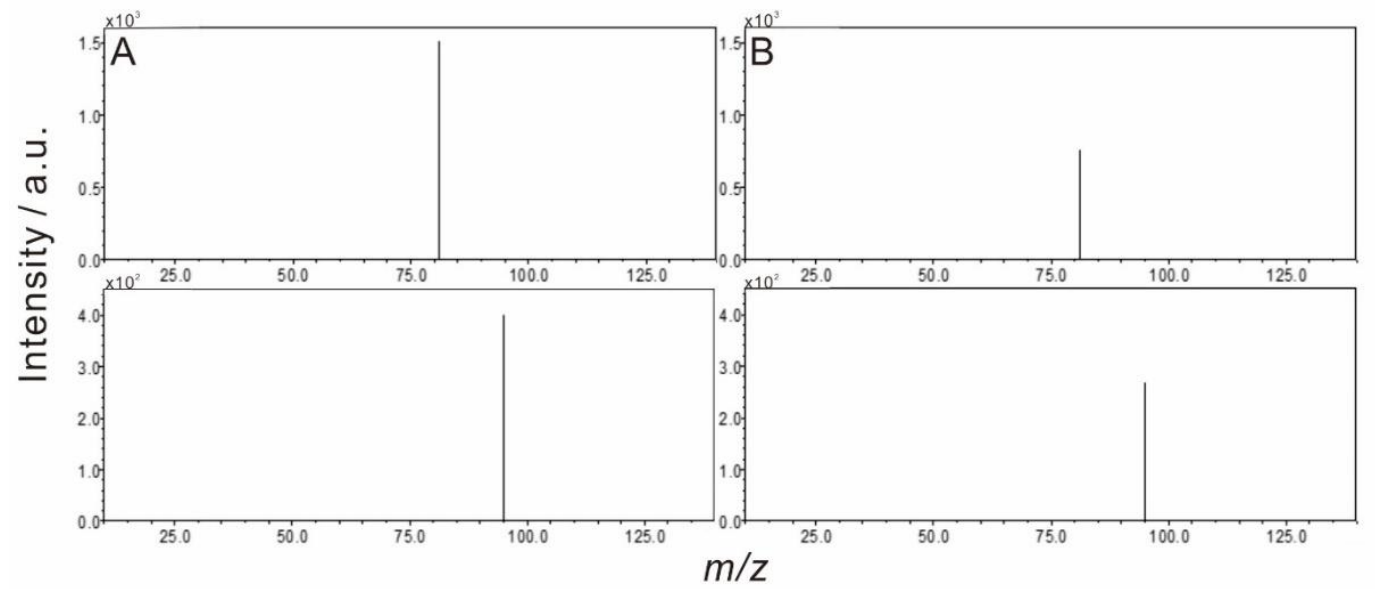

Figure S2. Estimation of analyte recovery during fizzy extraction of $0.3 \mathrm{mM}$ limonene (dissolved in water:ethanol 95:5, v/v). The liquid sample before (A) and after (B) one cycle of fizzy extraction was diluted $10 \times$ with a water:ethanol solution $(1: 1, \mathrm{v} / \mathrm{v})$, and infused to APCI-QQQMS instrument operated in the positive-ion multiple reaction monitoring mode. Sample flow rate: $30 \mu \mathrm{L} \mathrm{min}{ }^{-1}$. Parent ion $\mathrm{m} / \mathrm{z}$ : 137. Fragment ion $\mathrm{m} / \mathrm{z}: 81$ (first row) and 95 (second row). CID gas: argon. Collision voltage: $-20 \mathrm{~V}$. To calculate extraction recovery, a 1-min ion current was averaged. The recovery was computed based on the decrease of the average ion currents (at the $\mathrm{m} / \mathrm{z} 81$ ), recorded for the samples before and after fizzy extraction. One out of three replicate results is shown. 

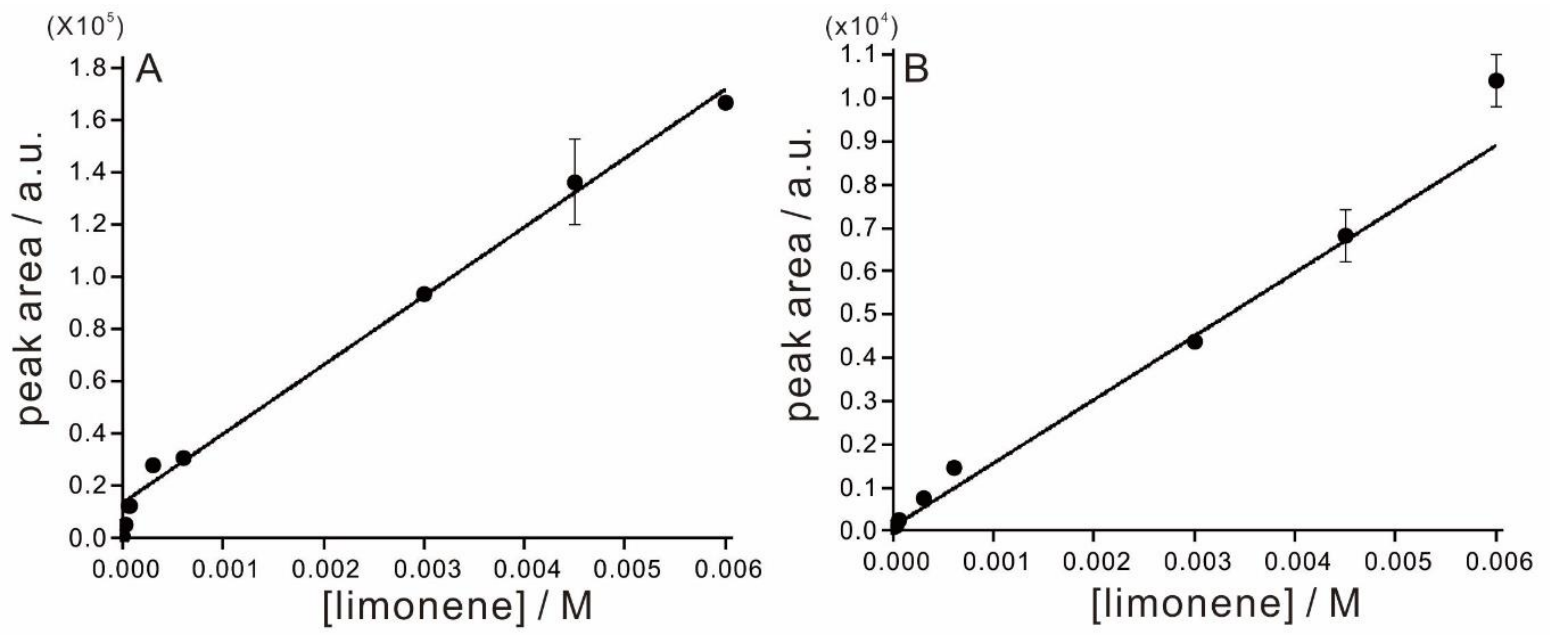

Figure S3. Calibration plots for fizzy extraction of limonene (dissolved in water:ethanol 95:5, v/v). (A) Full spectrum (Q3) scan; target ion $m / z$ : 137. (B) Selected reaction monitoring; parent ion $\mathrm{m} / \mathrm{z}$ 137; fragment ion $\mathrm{m} / \mathrm{z}$ 81; CID gas: argon; collision voltage: $-20 \mathrm{~V}$. Equation of the fitted line in $(\mathrm{A})$ : Peak_area $=\left(2.64 \times 10^{7} \pm 0.27 \times 10^{7}\right)[$ Limonene $]+\left(1.36 \times 10^{4} \pm 0.31 \times 10^{4}\right) ; R^{2}=0.932$; LOD $=3.9 \times 10^{-4} \mathrm{M}$. Equation of the fitted line in $(B):$ Peak_area $=\left(1.47 \times 10^{2} \pm 6.18\right)$ [Limonene] $+\left(9.63 \times 10^{-3} \pm 1.95 \times 10^{-3}\right) ; R^{2}=0.987 ;$ LOD $=4.4 \times 10^{-5} \mathrm{M}$. Error bars represent standard deviation $(n=3)$. 


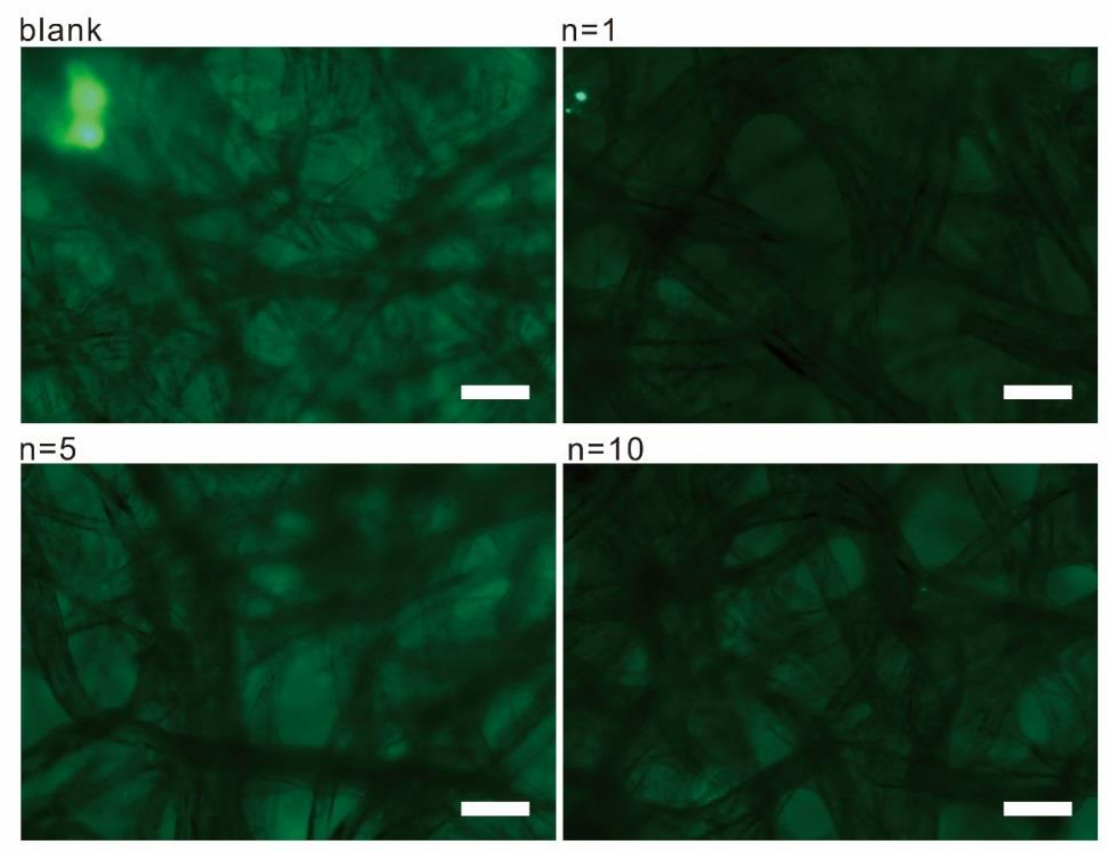

Figure S4. Off-line fizzy extraction of a fluorescein sample $\left(0.08 \mathrm{mg} \mathrm{mL}^{-1}\right.$ in dissolved in water:ethanol 95:5, v/v), with extract collection onto filter paper (Advantec, Dublin, USA). The fluorescence micrographs $\left(\lambda_{\mathrm{ex}}=460\right.$ to $500 \mathrm{~nm} ; \lambda_{\mathrm{em}}=510$ to $\left.560 \mathrm{~nm}\right)$ show the area of the filter paper exposed to the gaseous extract. Different numbers of extractions (n) have been tested. Note that the surface of paper exhibited some autofluorescence (bright spots in the blank paper area), probably due to the presence of fluorescent additives and contaminants. However, we did not observe an increase of fluorescence with the increasing number of extractions. Scale bars: $50 \mu \mathrm{m}$. 


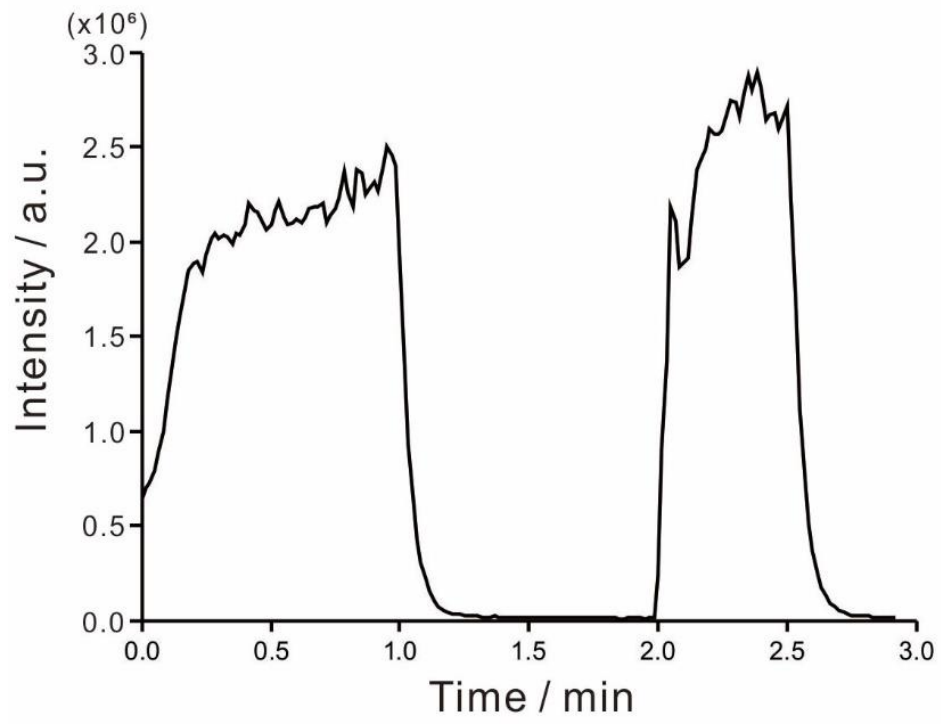

Figure S5. Fizzy extraction of a sample of $1 \mathrm{mM}$ ethyl acetate (dissolved in water:ethanol 95:5, v/v), $\mathrm{m} / \mathrm{z}$ 89. The height of the extraction feature $(2.0-2.7 \mathrm{~min})$ is comparable with the height of the flushing feature $(<1.2 \mathrm{~min})$. In this particular case, it is not necessary to conduct fizzy extraction because ethyl acetate is highly volatile. 


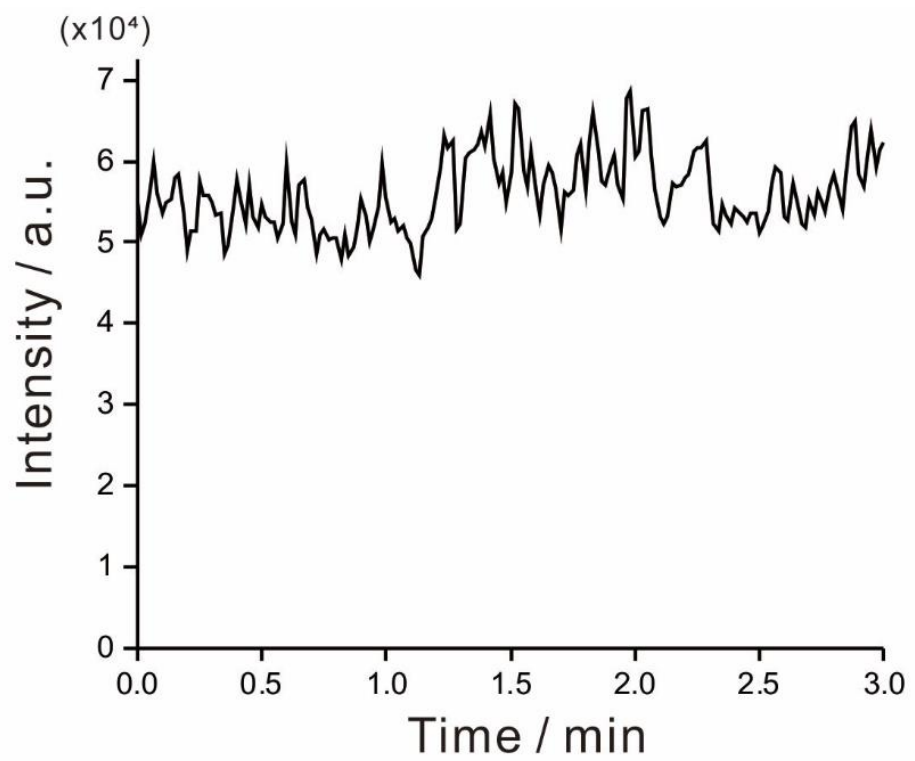

Figure S6. Fizzy extraction of a sample of $100 \mathrm{mM}$ caffeine (dissolved in water:ethanol 95:5, v/v), $\mathrm{m} / \mathrm{z}$ 195. In this case, the MS signal did not increase during headspace flushing or extraction due to the low volatility of caffeine. Please note the displayed ion intensity range is much smaller than in Figure S5. 


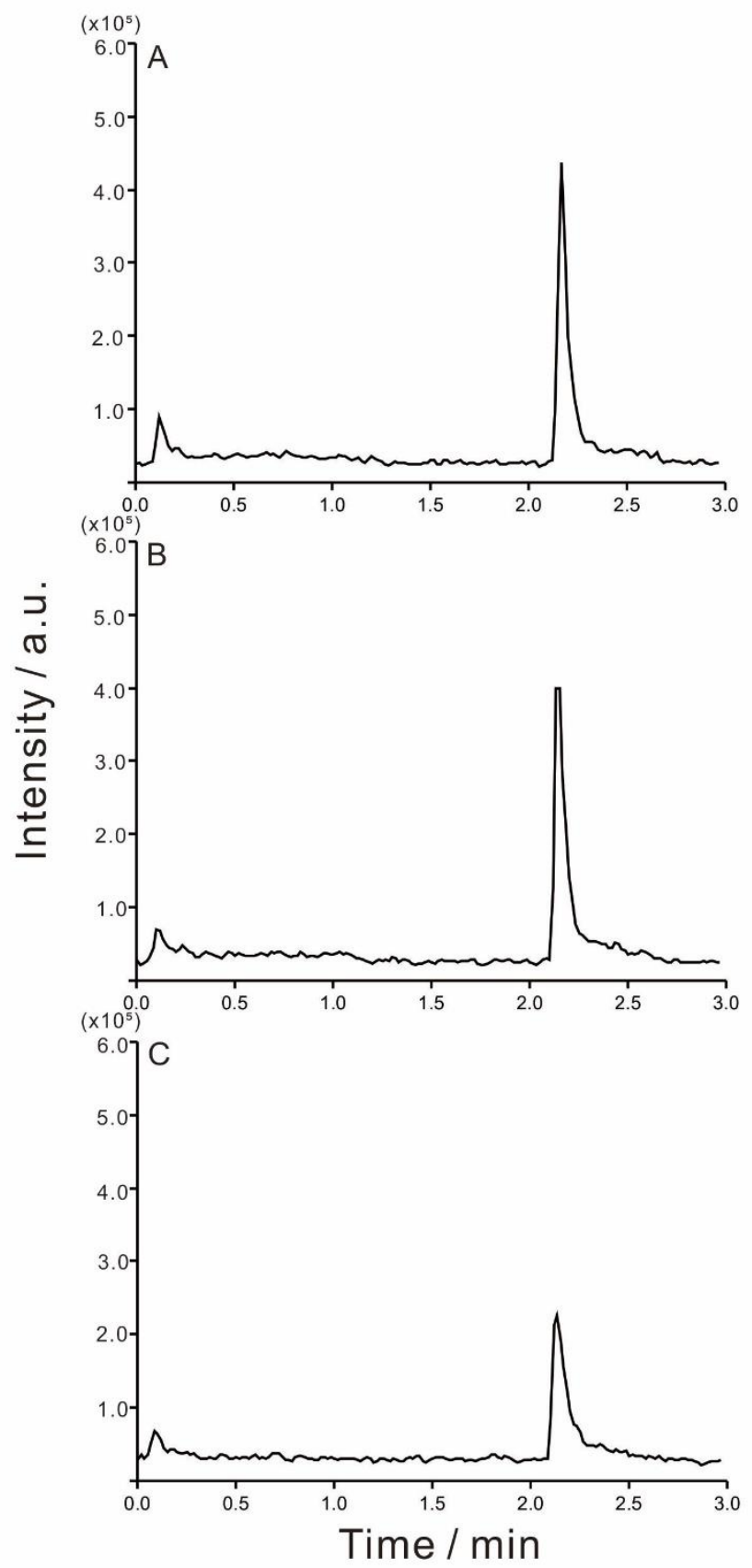

Figure S7. Effect of stirring during saturation and extraction steps: (A) stirrer is on during saturation and extraction; (B) stirrer is on during saturation and it is off during extraction; (C) stirrer is off during saturation and extraction. Fizzy extraction of $30 \mathrm{mM}$ limonene (dissolved in water:ethanol 95:5, v/v). Carrier gas: carbon dioxide. Carrier gas pressure: $150 \mathrm{kPa}$. Detector: APCI-QQQ-MS operated in full spectrum scan $(\mathrm{m} / \mathrm{z}$ range: $90-200)$, positive-ion mode. Target ion $m / z: 137$. 


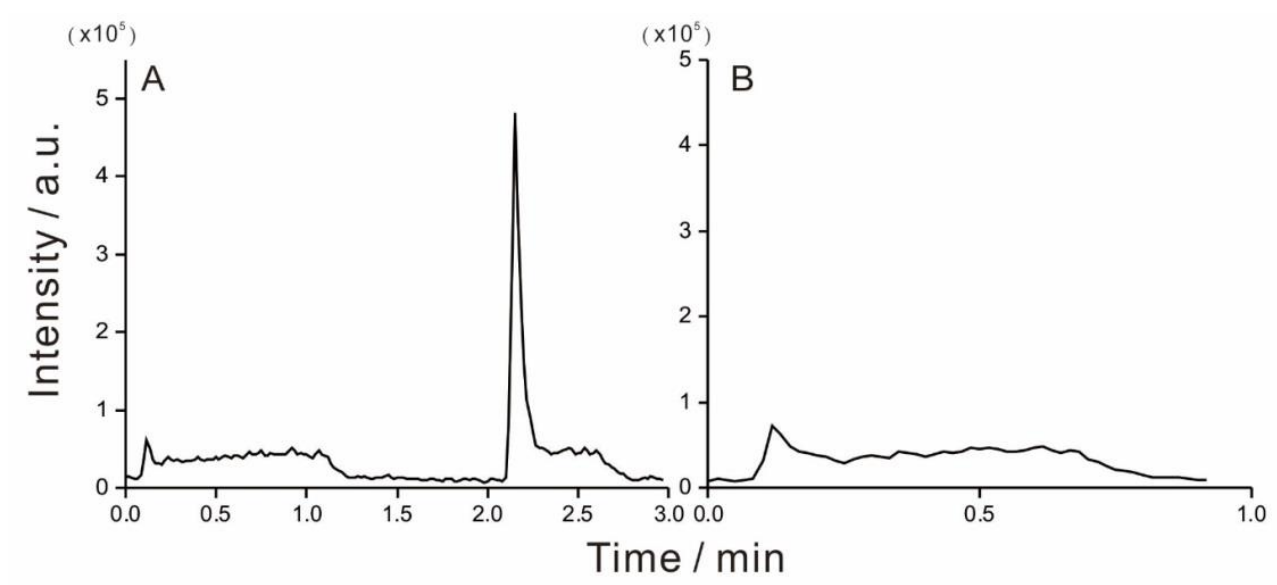

Figure S8. Comparison of the fizzy extraction (A) with an "extraction" by stirring (without saturating the sample with carbon dioxide) (B). In (A), the procedure was according to Table 1. In (B), the headspace was flushed with carbon dioxide only for $5 \mathrm{~s}$ to remove ambient air residue, and stirring was immediately switched on. The headspace effluent was then transferred to the APCIMS interface (Valve 2 open; $c f$. Figure 1A). Sample: $0.6 \mathrm{mM}$ limonene (dissolved in water:ethanol 95:5, v/v). Target ion $m / z: 137$. 